\title{
Cutaneous infection caused by Bacillus anthracis in Larissa, Thessaly, Central Greece, July 2012
}

A Stefos ${ }^{1}$, N K Gatselis ${ }^{1}$, A Goudelas², M Mpakarosi ${ }^{1}$, J Papaparaskevas³, G N Dalekos ${ }^{1}$, E Petinaki (petinaki@med.uth.gr)4

1. Department of Medicine and Research Laboratory of Internal Medicine, Medical School, University of Thessaly, Thessaly, Greece

2. Veterinary Authority in Larissa Prefecture, Thessaly, Greece

3. Department of Microbiology, Medical School, National and Kapodistrian University of Athens, Athens, Greece

4. Department of Microbiology, Medical School, University of Thessaly, Thessaly, Greece

Citation style for this article:

Stefos A, Gatselis NK, Goudelas A, Mpakarosi M, Papaparaskevas J, Dalekos GN, Petinaki E. Cutaneous infection caused by Bacillus anthracis in Larissa, Thessaly, Central Greece, July 2012. Euro Surveill. 2012;17(32):pii=20245. Available online: http://www.eurosurveillance.org/ViewArticle.aspx?Articleld=20245

Article submitted on 6 August 2012 / published on 9 August 2012

In July 2012, a confirmed case of cutaneous anthrax infection in a stockbreeder in the prefecture of Larissa, Thessaly, Central Greece was reported. The investigation revealed five related deaths in animals (two dogs and three sheep). Control measures have been taken immediately in order to prevent further spread in humans and animals.

On 7 July 2012, a stockbreeder in his early 60 s was admitted to the Department of Medicine, University Hospital of Larissa, Greece with high fever up to $39.5^{\circ} \mathrm{C}$ accompanied by rigors, malaise and generalised weakness that had been present for the previous six hours. The patient reported the appearance of three pruritic papular lesions on the left forearm five days earlier. He further reported that he had slaughtered and flayed a sheep six days before admission to hospital.

\section{Case description}

Upon hospital admission, the patient was febrile, his vital signs were normal, and during the physical examination three painless ulcers on the left forearm with surrounding vesicles and oedema, covered by black eschars were observed (Figure). The left axillary lymph nodes were significantly swollen. No other signs or symptoms were found during the physical examination.

Laboratory results on the day of hospital admission revealed elevation of acute phase response markers (white blood cells: 17,100/ $\mu$ L (range: 4,000-10,000/ $\mu \mathrm{L}$ ), neutrophils: $14,600 / \mu \mathrm{L}$ (range: $2,400-6,000 / \mu \mathrm{l}$ ), C-reactive protein: $3.5 \mathrm{mg} / \mathrm{dL}$ (range: $0.5 \mathrm{mg} / \mathrm{dL}$ )). A working diagnosis of cutaneous anthrax was established on the basis of the patient's place of residence and typical clinical presentation. Therefore, intravenous treatment with penicillin (24 million units per day) was started immediately [1]. After 10 days of hospitalisation, he was discharged in good health with clinical and laboratory results indicating complete recovery. Although the possibility of inhalation exposure in this case was very unlikely, the precise conditions of the direct contact that took place during flaying are not known. Therefore, upon discharge from hospital, the patient received amoxicillin (oral dose of $1,500 \mathrm{mg}$ per day) for an additional 45 days as a post-exposure prophylaxis against the potential development of anthrax pneumonitis.

\section{Laboratory investigation}

On 8 July, one day after hospitalisation of the patient, biological samples (smears from pustules) were sent to the Department of Microbiology at the Medical School of the University of Thessaly. Microscopic examination of the smears showed the presence of Gram-positive rods, typical for Bacillus anthracis. However, bacterial cultures remained negative; this finding could be explained by the fact that, at the time the samples were taken, the patient was already under penicillin treatment at a high dose.

Blood samples were obtained by the local veterinarian from two more sheep that have died in the same herd after 7 July. These two were also inspected and microscopic examination revealed the presence of

\section{FIGURE}

Skin lesions due to cutaneous anthrax infection, Larissa, Thessaly, Central Greece, July 2012

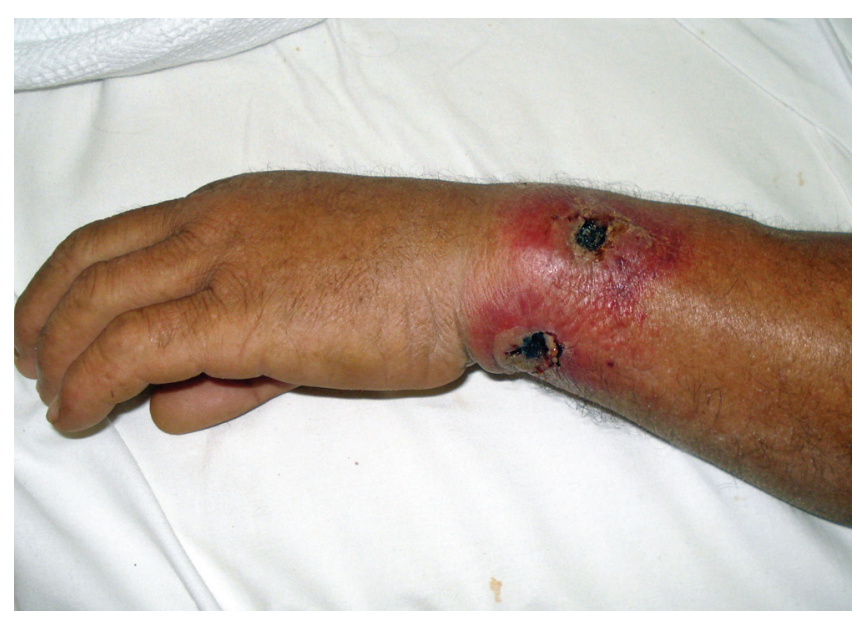


Gram-positive rods and bacterial cultures grown for $24 \mathrm{~h}$ on $5 \%$ blood agar produced grey-white colonies. Preliminary identification was performed using conventional methodology. Briefly, haemolysis detection and motility testing was performed as described previously, using $5 \%$ horse blood and trypticase soy broth (Bioprepare, BioPa Kerateas, Greece) [2]. Capsular testing was performed using nutrient agar plates supplemented with $0.7 \% \mathrm{NaHCO}_{3}$ (Bioprepare), incubated in $5 \% \mathrm{CO}_{2}$ for $24 \mathrm{~h}$, followed by McFadyen methylene blue staining. Genus and species confirmation, as well as detection of the two $B$. anthracis plasmids, $\mathrm{DXO}_{1}$ and $\mathrm{pXO} 2$, responsible for the species' pathogenicity, was performed using SYBR Green real-time PCR and the primer pairs $B A 813 \mathrm{~F} / \mathrm{R}, \mathrm{PAG} 67 / 68$ and $\mathrm{CAP} 57 / 58$, as well as the Genesig Bacillus anthracis Real Time PCR kit (PrimerDesign Ltd, Southampton, UK), which is based on TaqMan chemistry [3].

The microorganism isolated from the sheep was identified as $B$. anthracis and carried the two pathogenic plasmids $\mathrm{pXO}_{1}$ and $\mathrm{pXO} 2$; the $\mathrm{pXO}_{1}$ plasmid contains the lef, cya and pag genes, which encode the lethal factor, oedema factor and protective antigen, respectively, while the $\mathrm{pXO}_{2}$ plasmid contains the cap gene, which encodes the capsule [3].

\section{Epidemiological investigation}

The stockbreeder was contaminated after having handled the slaughtered sheep due to direct contact with the infected animal. He had flayed the animal together with his wife and then fed two dogs with the contaminated meat. These dogs died during the next day. After 36 hours, the specific anthrax cutaneous lesions appeared on the exposed area of the stockbreeder's skin. Since 7 July, two more sheep have died in the same herd. No other death occurred in this or other herd in the same village (Tsabournia).

It can be assumed that the stockbreeder's wife was also exposed to the spores of the infected animal. However, she did not present any signs or symptoms of infection and is now under post-exposure prophylactic treatment.

\section{Control measures}

The stockbreeder's wife hasn't developed any symptoms during the maximum incubation period of 15 days, but is currently receiving post-exposure prophylaxis. The residents of the village (Tsabournia) have been informed about this case in order to recognise early clinical symptoms of anthrax and they were advised to seek medical treatment immediately if anthrax was suspected. The local health centre and general practitioners are aware of this need for careful monitoring. Special directions have been given to the stockbreeders of Tsabournia regarding the use of protective equipment. The local Veterinary Authority has taken measures for the correct disposal of animal carcasses, including disinfection of contaminated material and decontamination of the environment. Mass vaccination of 7,000 animals is currently in progress.

\section{Background information}

Anthrax is an acute infectious disease caused by a large, spore-forming, toxin-producing bacterium $B$. anthracis [4]. It is the oldest known zoonosis with worldwide distribution and has been known to man for hundreds of years, mostly as an animal disease, typically in agricultural areas $[4,5]$. The disease is endemic in many countries of the world, particularly in tropical and sub-tropical areas, such as southern Europe, Asia, Africa, North and South America, and Australia [6,7]. It commonly occurs in well defined endemic areas where environmental conditions are particularly favourable for the survival of the spores. In Europe, there is a definite declining trend: The number of reported human cases remained at around 25 cases per year during a ten-year period (1995-2004), and has since decreased even more (2005: 10 cases, 2006: 16 cases, 2007: five cases, 2008: three cases, 2009: 14 cases) [8-12]. In the last four years, several reports of anthrax infections in heroin drug users have been reported in European countries [13-15].

Until 1979, Greece, particularly the northern part of the country, was considered as an enzootic zone for anthrax [6]. Although the number of animal outbreaks between 1970 and 1979 had declined to almost a quarter of that of the previous decade (1960-1969), there were 300 outbreaks a year, mostly involving sheep. During this period, there were 8,475 sheep and 1,675 bovine losses in 3,669 separate outbreaks. During the same period, 482 human anthrax cases occurred in the country and all patients were from rural areas [6]. The highest incidences were observed in the prefectures of Aetoloakarnania, Evros, Ioannina, Larissa, Rodopy and Thessaloniki [6]. Since then, strict control measures have eliminated the disease and only sporadic cases in animals and humans have been reported. According to the epidemiological reports from the European Centre for Disease Prevention and Control (ECDC), only 38 confirmed human cases of anthrax were reported between 1994 and 2010 [8-12]. However, it should be stated that although anthrax is included in the notifiable diseases and every suspected case should be reported to the Hellenic Center for Disease Control and Prevention (HCDCP), there is some degree of underreporting and the low number of reported cases does not allow general conclusions regarding the accurate incidence trend.

Thessaly is a rural region located in Central Greece and includes four prefectures (Karditsa, Larissa, Magnesia, Trikala). The estimated number of goats and sheep in this region is above 2 million. The large majority of them (more than 1 million goats and sheep) are farmed in Larissa prefecture. According to the records of the local Veterinary Authority of Larissa, three outbreaks of anthrax have been reported in Larissa in the past 35 years (in 1978, in 2000, and in 2006) (unpublished 
data). All of them occurred in herds kept in two villages (Livadi and Tsabournia) situated at a distance of $35 \mathrm{~km}$ from each other in the area of Elassona, Larissa prefecture. Approximately 90 animals were affected in total, and the outbreaks were contained after correct disposal of animal carcasses and vaccination of exposed animals. According to the epidemiological data of the Veterinary Authority, no case of anthrax in animals or humans has ever been declared in the other three prefectures of Thessaly.

In 1978, anthrax infection had been confirmed in animals of three different herds in Tsabournia. However, no human infection has been reported. Vaccination and appropriate control measures have been taken; since then until the incident described here no other anthrax case in animals or in humans has been reported.

\section{Conclusions}

From a public health point of view, anthrax is important for Europe as well as for other regions. Infections still occur in Greece and clinicians should be aware of the disease and of the need for immediate management and reporting to the HCDCP [16].

In the management of the case described above, the level of post-prophylactic treatment may be seen as unusual according to the World Health Organization (WHO) recommendations (no post-prophylactic treatment required in a patient previously treated by intravenous penicillin) [1]. Here, post-exposure prophylaxis was nevertheless recommended after hospital discharge because the precise conditions of direct contact which took place during flaying were not clearly known [17].

Early recognition of this suspected human case and reporting to the local authorities without delay have led to the prevention of further spread of the disease both in humans and animals.
References

1. World Organisation for Animal Health (OIE), World Health Organization (WHO), Food and Agriculture Organization of the United Nations (FAO). Anthrax in humans and animals. Fourth edition. Geneva: WHO; 2008. Available from: http://whqlibdoc. who.int/publications/2008/9789241547536_eng.pdf

2. Papaparaskevas J, Houhoula DP, Papadimitriou M, Saroglou G, Legakis NJ, Zerva L. Ruling out Bacillus anthracis. Emerg Infect Dis. $2004 ; 10(4): 732-5$.

3. Fasanella A, Losito S, Trotta T, Adone R, Massa S, Ciuchini $\mathrm{F}$, et al. Detection of anthrax vaccine virulence factors by polymerase chain reaction. Vaccine. 2001;19(30):4214-8.

4. Anthrax, In: Merck Veterinary Manual, National Publishing Inc. eighth edition, 1998. Philadelphia, p 432-5.

5. Anthrax, In Veterinary Medicine, Saunders, eighth edition, 1997. London p. 671-6.

6. Velimirovic B. Anthrax in Europe. Rev Sci Tech Off Int Epiz. 1984;3(3): 527-59.

7. Dragon DC, Rennie RP. The ecology of anthrax spores: tough but not invincible. Can Vet J. 1995;36(5):295-301.

8. European Centre for Disease Prevention and Control (ECDC). Annual epidemiological report on communicable diseases in Europe. Stockholm: ECDC. 2007. Available from: http://ecdc. europa.eu/en/publications/Publications/0706_SUR_Annual_ Epidemiological_Report_2007.pdf

9. European Centre for Disease Prevention and Control (ECDC). Annual epidemiological report on communicable diseases in Europe 2008. Stockholm: ECDC. 2008. Available from: http:// ecdc.europa.eu/en/publications/Publications/0812_SUR_ Annual_Epidemiological_Report_2008.pdf

10. European Centre for Disease Prevention and Control (ECDC). Annual epidemiological report on communicable diseases in Europe 2009. Stockholm: ECDC. 2009. Available from: http://ecdc.europa.eu/en/publications/Publications/o910 SUR Annual_Epidemiological_Report_on_Communicable Diseases_in_Europe.pdf

11. European Centre for Disease Prevention and Control (ECDC). Annual epidemiological report on communicable diseases in Europe 2010. Stockholm: ECDC. 2010. Available from: http://ecdc.europa.eu/en/publications/Publications/1011 SUR_Annual_Epidemiological_Report_on_Communicable_ Diseases_in_Europe.pdf

12. European Centre for Disease Prevention and Control (ECDC). Annual epidemiological report 2011. Reporting on 2009 surveillance data and 2010 epidemic intelligence data. Stockholm: ECDC. 2011. Available from: http://ecdc. europa.eu/en/publications/Publications/1111_SUR_Annual Epidemiological_Report_on_Communicable_Diseases_in Europe.pdf

13. Radun D, Bernard H, Altmann M, Schöneberg I, Bochat V, van Treeck U, et al. Preliminary case report of fatal anthrax in an injecting drug user in North-Rhine-Westphalia, Germany, December 2009. Euro Surveill. 2010;15(2): pii=19464. Available from: http://www.eurosurveillance.org/ViewArticle. aspx?Articleld $=19464$

14. Holzmann T, Frangoulidis D, Simon M, Noll P, Schmoldt $S$, Hanczaruk $M$, et al. Fatal anthrax infection in a heroin user from southern Germany, June 2012. Euro Surveill. 2012;17(26):pii=20204. Available from: http://www. eurosurveillance.org/ViewArticle.aspx?Articleld=20204

15. Palmateer NE, Ramsay CN, Browning L, Goldberg DJ, Hutchinson SJ. Anthrax infection among heroin users in Scotland during 2009-2010: a case-control study by linkage to a national drug treatment database. Clin Infect Dis. 2012;55(5):706-10.

16. Karpouzis A, Panopoulou M, Bazzano G, Grapsa A, Maltezos $E$, Ktenidou-Kartali $S$, et al. Extensive cutaneous anthrax in an immunocompetent patient. Eur J Dermatol. 2007;17(5):443-5.

17. Weber DJ, Rutala WA. Risks and prevention of nosocomial transmission of rare zoonotic diseases. Clin Infect Dis. 2001;32(3):446-56. 